Bernhard Braun

Das Feuer des Eros

Platon zur Einführung 



\section{Bernhard Braun}

\section{Das Feuer des Eros}

Platon zur Einführung

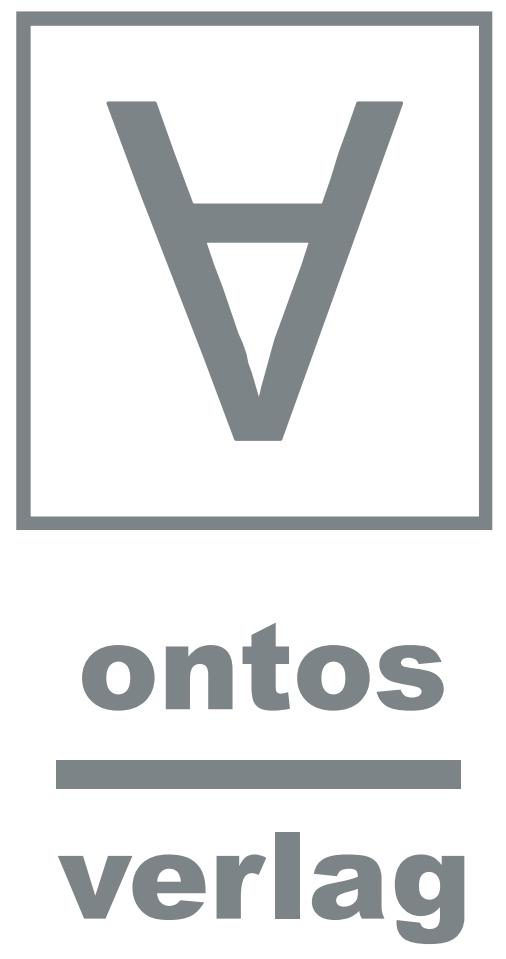

Frankfurt - Lancaster 
Bibliographic information published by Die Deutsche Bibliothek

Die Deutsche Bibliothek lists this publication in the Deutsche Nationalbibliographie; detailed bibliographic data is available in the Internet at http://dnb.ddb.de

${ }^{\circ} 2004$ ontos verlag

Frankfurter Str. $39 \bullet 63150$ Heusenstamm b. Frankfurt Tel. ++(49) 6104665733 Fax ++(49) 6104665734 www.ontos-verlag.com

ISBN 3-937202-37-4

2004

Alle Texte, etwaige Grafiken, Layouts und alle sonstigen schöpferischen Teile dieses Buches sind u.a. urheberrechtlich geschützt. Nachdruck, Speicherung, Sendung und Vervielfältigung in jeder Form, insbesondere Kopieren, Digitalisieren, Smoothing, Komprimierung, Konvertierung in andere Formate, Farbverfremdung sowie Bearbeitung und Übertragung des Werkes oder von Teilen desselben in andere Medien und Speicher sind ohne vorherige schriftliche Zustimmung des Verlages unzulässig und werden verfolgt.

Gedruckt auf säurefreiem, alterungsbeständigem Papier, hergestellt aus chlorfrei gebleichtem Zellstoff (TcF-Norm).

Printed in Germany. 
aben wissenschaftlich-technische Welteroberung auf der einen und Spiritualität und Mystik auf der anderen Seite etwas gemeinsam? Die Frage wird Sie überraschen. Steht nicht Wissenschaft für rationales, methodisch exaktes und intersubjektiv nachvollziehbares Vorgehen, die Mystik dagegen für eine sehr subjektive Erfahrung eines radikalen Ausbruchs aus dem Vertrauten und Alltäglichen? Und doch! Es ist die archaische Figur des Eros, der für das Zerreissen und Versöhnen gleichermaßen das Symbol abgibt. Es geht daher in diesem Buch um Technik und Wissenschaft, anders gesagt: um die Begegnung des Menschen mit der Natur. Und es geht um Mystisches, anders gesagt: um die Begegnung des Menschen mit Gott-oder mit sich selbst.

Der Gott Eros stammt aus dem Orient und ist in seinen Ursprüngen ein Zerreisser dieser Welt. Er wirft sie aus dem Takt und zerstört ihre Harmonie. Das jedoch war für die frühen griechischen Philosophen, damit für die Gründer der sich bildenden abendländischen Identität, eine Kampfansage.

Eros wurde in einem aufregenden Akt kultureller Aneignung und Identitätsstiftung umgedeutet. Er wurde vom Zerreisser zum Versöhner, zu eben jener Kraft, die die zerbrochene Welt wieder heilt. Dies spielt sich mit didaktischer Brillanz im Denken des großen Philosophen Platon ab. Zu ihm ist Alfred North Whitehead einmal das nicht unzutreffende Bonmot eingefallen, die restliche Philosophiegeschichte des Abendlands bestünde nur in Fußnoten zu seinem Werk.

Platon entwirft einen Eros, der sowohl die Urfigur für die spirituelle Kraft der Begegnung von Menschlichem und Göttlichem abgibt, als auch den Antrieb für den Nachbau einer unverletzten, heilen Welt. Ein Blick auf die Texte dieses Philosophen erschließt ein tieferes Verständnis für die feurige Leidenschaftlichkeit des Fortschritts, den wir hassen und lieben, der uns befreit und knechtet, der uns Hoffnung ist und Angst auslöst und von dem wir doch - so scheint es - nicht loskommen. 